Original Article

\title{
FREQUENCY OF REMISSION AFTER TREATMENT WITH HYPER CVAD PROTOCOL IN NEWLY DIAGNOSED PATIENTS OF ACUTE LYMPHOBLASTIC LEUKEMIA PRESENTING TO JINNAH HOSPITAL LAHORE
}

Muhammad Kashif ${ }^{a}$, Tahir Mehmood ${ }^{\mathrm{b}}$, Kausar Bano ${ }^{c}$, Muhammad Akram $^{\mathrm{d}}$, Muhammad Imran Khan ${ }^{\mathrm{e}}$, Tehreem Fatima $^{f}$

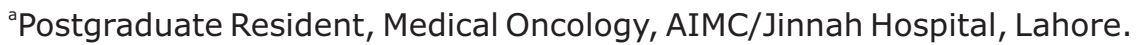

${ }^{\text {b} C o n s u l t a n t ~ M e d i c a l ~ O n c o l o g i s t, ~ F M U / A l l i e d ~ H o s p i t a l, ~ F a i s a l a b a d . ~}$

${ }^{\mathrm{c}}$ Assistant Professor, Medical Oncology, AIMC/Jinnah Hospital, Lahore.

dProfessor and Head Department of Oncology, AIMC/Jinnah Hospital, Lahore.

${ }^{\text {e}}$ Assistant Professor, Radiology, FJMU/Sir Ganga Ram Hospital, Lahore.

${ }^{f}$ Research Assistant, Biochemistry, Government College University, Faisalabad.

\section{ABSTRACT:}

OBJECTIVE: The objective of this study was to determine the frequency of complete and partial remission after 2 courses of hyper CVAD regimen in newly diagnosed patients of acute lymphoblastic leukemia (ALL).

MATERIAL AND METHODS: This study was conducted on 100 patients of ALL presenting to the oncology department of Jinnah Hospital, Lahore and fulfilling the inclusion criteria from 01-012016 to 30-12-2016. Patients were undergone treatment with hyper CVAD regimen according to the standard protocol. Complete or partial remission rate was checked after 2 session of hyper CVAD regimen. CT scan (chest and abdomen) was performed for confirmation of extramedullary disease.

RESULTS: The mean age of study population was $35.68 \pm 8.69$ years. There were $48 \%$ male patients while female patients were $52 \%$. Complete remission was present in $72 \%$ patients. Partial remission was present in $24 \%$ patients. There was no significant association between complete remission and age $(p$-value $=0.497)$. No significant association was found between partial remission and age $(p$-value $=0.103)$. Significant association was found between partial remission and complete remission with gender having $p$-value $=0.001$ and 0.01 respectively.

CONCLUSION: The frequency of complete and partial remission after 2 courses of hyper CVAD regimen in newly diagnosed patients of ALL was $72 \%$ and $24 \%$ respectively. Effect modifiers have no significant influence except gender.

KEYWORDS: Acute Lymphoblastic Leukemia, Complete and Partial Remission, Hyper CVAD.

\section{INTRODUCTION:}

Acute lymphoblastic leukemia (ALL) alludes to a gathering of hematopoietic neoplasms including cells focused on the lymphoid heredity. Philadelphia chromosome positive ALL $(P h+A L L)$ is a naturally and clinically unmistakable variation of ALL delegated with $\mathrm{t}(9 ; 22)(\mathrm{q} 34 ; \mathrm{q} 11.2) ; \mathrm{BCR}-\mathrm{ABL} 1$ in the WHO arrangement system ${ }^{[1]}$. $P h+A L L$ represents around 20 to 30 percent of ALL in adults and 2 to 3 percent of ALL in youngsters ${ }^{[2,3]}$. At the point when treated with chemotherapy alone, patients with $\mathrm{Ph}+\mathrm{ALL}$ have a consistently poor anticipation with couple of survivors at five years after treatment. Allogeneic hematopoietic cell transplantation (allo-HCT) gives better outcomes, relieving around 30 to 60 percent of patients with $\mathrm{Ph}+\mathrm{ALL}$. The fuse of BCR-ABL1 tyrosine kinase inhibitor (eg, imatinib, dasatinib) into the treatment regimen has brought about unrivaled remission rates, thereby enabling more patients to continue to

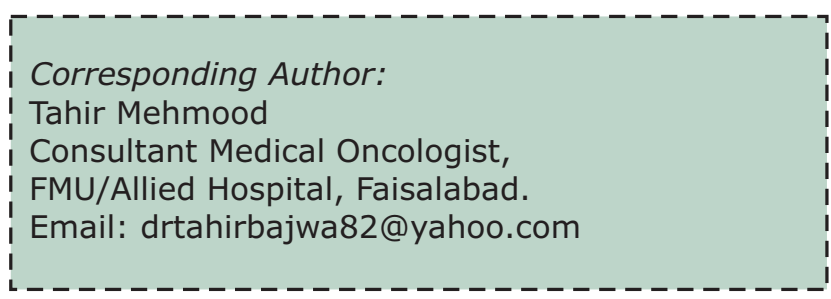

JUMDC Vol. 10, Issue 4, October-December 2019 
(allo-HCT) It is not yet known whether treatment with chemotherapy in addition to a tyrosine kinase inhibitor will give durable long haul abatements and preferable survival over allo-HCT. The treatment of Ph+ALL is particular from that of different sorts of ALL and involves a few phases that, altogether, may traverse three years of treatment.

More than 80 percent of adult patients with $\mathrm{Ph}+\mathrm{ALL}$ will accomplish a total abatement (CR) with acceptance chemotherapy that joins a tyrosine kinase inhibitor. Not with standing, without extra cytotoxic treatment, for all intents and purposes these patients will backslide inside half a month or months in spite of proceeding with tyrosine kinase inhibitor. Conversely, patients who get post-induction treatment may expect five-year survival rates of 40 to 60 percent. Post-induction treatment incorporates an about allo-HCT or the continuation of chemotherapy in addition to tyrosine kinase inhibitor.

More than 90 percent of adult patients with $\mathrm{Ph}+\mathrm{ALL}$ will achieve a hematologic finish remission (CR) with acceptance chemotherapy that joins a tyrosine kinase inhibitor (TKI). In any case, without extra cytotoxic treatment, for all intents and purposes these patients will backslide inside fourteen days or months. In contrast, patients who get post-induction therapy may expect five-year survival rates of 40 to 60 percent $^{[4]}$.

Autologous HCT permits the utilization of myeloablative chemotherapy and isn't related with GVHD, yet does not furnish the GVL impact seen with allogeneic HCT. Treatment related dismalness and mortality are generally low $(\leq 6 \%)$. Auto-HCT following imatinib-or dasatinib containing acceptance treatment yields a promising sub-atomic reduction, and individual long haul survivors have been depicted $^{[5,6]}$.

Non-myeloablative chemotherapy has a low treatment related death rate $(<5 \%)$. Significant adverse reactions are commonly present and incorporate pancytopenia, hepatic debilitation, and neuropathy. Before the availability of TKIs, patients with $\mathrm{Ph}+\mathrm{ALL}$ had a consistently poor anticipation with couple of survivors at five years after treatment with chemotherapy alone [7-14].

\section{METHODOLOGY:}

This cross sectional study was conducted on 100 patients of $A L L$, presenting to the oncology department of Jinnah Hospital, Lahore and fulfilling the inclusion criteria from 01-01-2016 to 30-12-2016. Information regarding their demographic data was noted in the proforma. Patients underwent treatment with hyper CVAD regimen according to the standard protocol. Complete or partial remission rate was checked after 2 session of hyper CVAD regimen. All patients undergone complete blood count after taking $3 \mathrm{ml}$ of blood sample under aseptic technique along with CT scan (chest and abdomen) for confirmation of extramedullary disease. They were also undergone bone marrow biopsy and examination by consultant histopathologist and results were noted in the proforma as well. Confidentiality of the data was ensured.

\section{RESULTS:}

From 100 patients, it was observed that the minimum age was 20 years and maximum age was 50 years with mean and standard deviation of the age was $35.68 \pm 8.69$ years. There were $48 \%$ male patients while female patients were $52 \%$. Complete remission was present in $72 \%$ patients while complete remission was not present in $28 \%$ patients $(p=0.001)$ in table-I. Partial remission was present in $24 \%$ patients while partial remission was not present in $76 \%$ patients

$(p=0.01)$ in table-II. By applying chi-square test, there is no significant association between complete remission and age having $p$ value $=0.497$ It observed that significant association is not found between partial remission and age having $p$-value $=0.103$. There is significant association between complete remission and gender having $p$ value $=0.001$ in table-I, also with partial remission with gender having $p$-value $=0.01$ in table-II. 
Table-I: Distribution of patients by complete remission $(n=100)$

\begin{tabular}{|c|c|c|c|}
\hline \multirow{2}{*}{ Gender } & \multicolumn{2}{|c|}{ Complete remission } & \multirow{2}{*}{ Total } \\
\cline { 2 - 3 } & Yes & No & 48 \\
\hline Male & 31 & 17 & 52 \\
\hline Female & 41 & 11 & 100 \\
\hline Total & 72 & 28 & \\
\hline
\end{tabular}

$X^{2}=16.3$ P-value $=0.001$

Table-II: Distribution of patients by partial remission $(n=100)$

\begin{tabular}{|c|c|c|c|}
\hline \multirow{2}{*}{ Gender } & \multicolumn{2}{|c|}{ Partial remission } & \multirow{2}{*}{ Total } \\
\cline { 2 - 3 } & Yes & No & 48 \\
\hline Male & 14 & 34 & 52 \\
\hline Female & 10 & 42 & 100 \\
\hline Total & 24 & 76 & \\
\hline
\end{tabular}

$\mathrm{X}^{2}=12.1 \mathrm{P}$-value $=0.01$

\section{DISCUSSION:}

In our investigation the mean age was $35.7 \pm 8.7$ years. There were $48 \%$ male and $52 \%$ female patients. Finish reduction (CR) was available in $72 \%$ patients. Halfway abatement was available in $24 \%$ patients. As indicated by the investigation of Terwilliger et $\mathrm{al}^{[15]}$ Acute lymphoblastic leukemia (ALL) is the second most acute leukemia in grown-ups, with an occurrence of more than 6500 cases for every year in the United States alone. In grown-ups, $75 \%$ of cases create from antecedents of the Bcell genealogy, with the rest of cases comprising of dangerous T-cell forerunners. Generally, chance stratification has been founded on clinical factors such as age, white platelet check and reaction to chemotherapy; in any case, the recognizable proof of intermittent hereditary changes has refined individual guess and guide the executives ${ }^{[15]}$.

In an investigation led in Iran, three hundred and one patients experienced changed hyperCVAD chemotherapy regimen. Finish reduction and in general survival (OS) rates were estimated as essential endpoints. About $81.7 \%$ achieved finish abatement amid the initial a half year of treatment ${ }^{[16]}$.

Past examination demonstrated that 34\% patients were determined to have ALL, and included $53 \%$ males and $47 \%$ females with a mean age of 34 years. Acceptance chemotherapy with healing expectation was managed to $94 \%$ patients. Twenty-seven patients got intrathecal chemotherapy as prophylaxis $(n=24)$ or as treatment for CNS involvement $(n=3)$. Twenty-eight patients (82\%) accomplished finish abatement (CR) after enlistment chemotherapy. The median survival (OS) time was 22 months and the fiveyear OS for ALL patients was $38 \%$. The median disease free survival (DFS) time was a year, while the five-year DFS was $38 \%$. Multivariate investigation demonstrated that age $<40$ years, WBC $<30 \times 109 / L$, accomplishment of CR after first acceptance, and CNS prophylaxis were prescient components for OS and DFS ${ }^{[17]}$.

In another examination, 185 patients (91\%) accomplished finish reduction (CR) and 12 (6\%) kicked the bucket amid enlistment treatment. Evaluated 5-year survival and 5-year CR rates were $39 \%$ and $38 \%$, individually. The frequency of CNS backslide was low (4\%). Contrasted and 222 patients treated with vincristine, doxorubicin, and dexamethasone (VAD) regimens, our patients had a superior CR rate $(91 \% \vee 75 \%, \mathrm{P}<0.01)$ and $\mathrm{CR}$ rate after one course $(74 \% \vee 55 \%, P<0.01)$ and better survival $(P<0.01)$, and a littler rate had over $5 \%$ day 14 impacts (34\% V 2.48\%, $\mathrm{P}=0.01$ ). Hyper-CVAD treatment is better than our past regimens and ought to be contrasted and set up regimens in grown-up ALL ${ }^{[18]}$. 


\section{CONCLUSION:}

The achievement of finish (CR) and incomplete reduction (PR) after 2 courses of hyper CVAD regimen in recently analyzed patients of Acute lymphoblastic leukemia was $72 \%$ and $24 \%$ separately. Impact modifiers have no noteworthy impact with the exception of gender.

\section{CONFLICT OF INTEREST:}

There is no declared conflict of interest.

\section{ETHICAL REVIEW COMMITTEE:}

Ethical review committee of the said institute has reviewed and approved this article.

\section{REFERENCES:}

1. Swerdlow SH, Campo E, Harris NL. World Health Organization Classification of Tumours of Haematopoietic and Lymphoid Tissues. IARC Press, Lyon 2008.

2. Moorman AV, Harrison CJ, Buck GA. Karyotype is an independent prognostic factor in adult acute lymphoblastic leukemia (ALL): analysis of cytogenetic data from patients treated on the Medical Research Council (MRC) UKALLXII/Eastern Cooperative Oncology Group (ECOG) 2993 trial. Blood 2007; 109:3189.

3. Jones LK, Saha V. Philadelphia positive acute lymphoblastic leukaemia of childhood. Br J Haematol 2005; 130:489.

4. Pfeifer H, Goekbuget N, Volp C. Longterm outcome of 335 adult patients receiving different schedules of imatinib and chemotherapy as frontline treatment for Philadelphia-positive acute lymphoblastic leukemia ( $\mathrm{Ph}+$ ALL) [abstract]. Blood (ASH Annual Meeting Abstracts) 2010; 116:Abstract 173.

5. Bassan R, Rossi G, Pogliani EM. Chemotherapy-phased imatinib pulses improve long-term outcome of adult patients with Philadelphia chromosome-positive acute lymphoblastic leukemia: Northern Italy Leukemia Group protocol 09/00. J Clin Oncol 2010; 28:3644.

6. Wetzler M, Stock W, Donohue KA. Autologous stem cell transplantation ( SCT) following sequential chemotherapy and imatinib for adults with newly diagnosed Philadelphia chromosome positive acute lymphoblastic leukemia (Ph+ CED-CCO Special Advice Report \#1014 ALL)CALGB study 10001 [abstract]. Blood (ASH Annual Meeting Abstracts) 2007; 110: Abstract 2869.

7. Larson RA, Dodge RK, Bloomfield CD, Schiffer CA. Treatment of biologically determined subsets of acute lymphoblastic leukemia in adults: Cancer and Leukemia Group B studies. In: Acute Leukemias VI: Prognostic factors and treatment strategies, Buchner T, Hiddeman W, Wormann B, et al. (Eds), Springer-Verlag, Berlin 1997. p.677.

8. Surapolchai $P$, Anurathapan $U$, Sermcheep A, Pakakasama S, Sirachainan N, Songdej D, et al. Longterm outcomes of modified st jude children's research hospital total therapy XIIIB and XV protocols for thai children with acute lymphoblastic leukemia. Clin Lymphoma Myeloma Leuk 2019;19(8):497-505.

9. Jalaeikhoo H, Rajaeinejad M, Keyhani M, Zokaasadi M, Dehghani Firoozabadi MM. Effectiveness of modified hyperCVAD chemotherapy regimen in the treatment of adult acute lymphoblastic leukemia: a retrospective experience. Cancer Med 2018;7(3):594-599.

10. Lepretre S, Touzart A, Vermeulin T, Picquenot JM, Tanguy-Schmidt A, et al. Pediatric-like acute lymphoblastic leukemia therapy in adults with 
Iymphoblastic lymphoma: The GRAALL-LYSA LL03 Study. J Clin Oncol 2016;34(6):572-80.

11. Onizuka M. [Current management of adult Philadelphia chromosomepositive acute lymphoblastic leukemia]. Rinsho Ketsueki. 2018;59 (10):2028-2035.

12. Gleissner B, Gökbuget N, Bartram CR. Leading prognostic relevance of the $B C R-A B L$ translocation in adult acute B-lineage lymphoblastic leukemia: a prospective study of the German Multicenter Trial Group and confirmed polymerase chain reaction analysis. Blood 2002; 99:1536.

13. Aldoss I, Forman SJ, Pullarkat V. Acute Lymphoblastic Leukemia in the Older Adult. J Oncol Pract 2019;15(2):6775.

14. Bao XB, Cai WZ, He XF, Chen SN, Qiu $H Y$, Sun AN, et al. Risk Factors of Leukemia-free Survival in $\mathrm{Ph}(+) \mathrm{ALL}$ Patients with Allogeneic Hematopoietic Stem Cell Transplantation]. Zhongguo Shi Yan Xue Ye Xue Za Zhi. 2017;25 (6): 1787-1792.

15. Terwilliger $T$, Abdul-Hay $M$. Acute Iymphoblastic leukemia: a comprehensive review and 2017 update. Blood cancer journal. 2017 Jun;7(6):e577. M, Zokaasadi M, Firoozabadi D, Mehdi $M$. Effectiveness of modified hyperCVAD chemotherapy regimen in the treatment of adult acute lymphoblastic leukemia: a retrospective experience. Cancer Med 2018 Jan 31.
16. Jalaeikhoo H, Rajaeinejad M, Keyhani

17. Paul S, Kantarjian H, Jabbour EJ. Adult Acute Lymphoblastic Leukemia. Mayo Clin Proc 2016;91(11):1645-1666..

18. Widmer $F$, Balabanov $S$, Soldini D, Samaras P, Gerber B, Manz MG, et al. R-hyper-CVAD versus R-CHOP/ cytarabine with high-dose therapy and autologous haematopoietic stem cell support in fit patients with mantle cell lymphoma: 20 years of singlecenter experience. Ann Hematol 2018; 97(2):277-287.

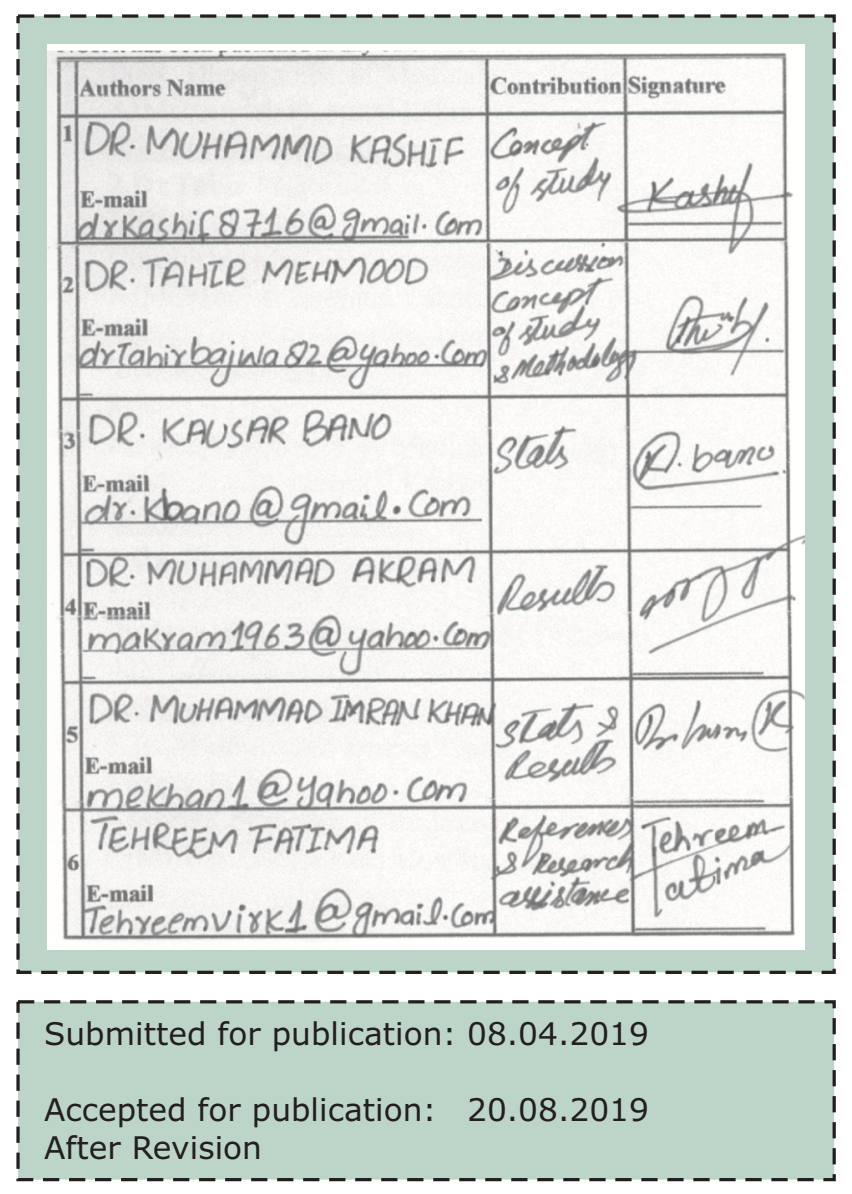

